\title{
LA RESPONSABILIDAD DEL EXTRANEUS EN EL MARCO DE LOS DELITOS ESPECIALES. UNA VISIÓN DEL PRINCIPIO DE UNIDAD DE TÍTULO DE IMPUTACIÓN*
}

\author{
The responsibility of extraneus in the framework of special crimes \\ A vision of the principle of unity of title of imputation
}

María Soledad RAMÍREZ MORALES

\begin{abstract}
Sumario:
I. Introducción II. Punto de partida. Diferencia entre delitos especiales propios e impropios III. Lo propio y lo impropio de los delitos especiales IV. Autoría y participación IV.1. Autoría en los delitos especiales IV.2. Participación en los delitos especiales IV.3. Principio de accesoriedad V. Teorías respecto a la intervención del extraneus en los delitos especiales V.1. Teoría de la ruptura del título de imputación V.2. Teoría de la unidad del título de imputación VI. Reflexión final VII. Bibliografía.
\end{abstract}

Resumen: Los delitos especiales sobresalen, precisamente, por tener un elemento importante en su descripción, es decir, ser ejecutados únicamente por un agente con cualidades especificas. De lo anterior se desprende la siguiente incógnita: ¿cuál es la responsabilidad del sujeto que participa en un delito especial y que no cumple con las cualidades determinadas de dicho tipo? Este tema es una interrogante discutida por juristas y dogmáticos, respecto a la autoría y participación en la ejecución de estos hechos típicos.

Por esta razón, en el presente trabajo se pretende analizar y puntualizar la responsabilidad penal del agente extraño al ser parte de la realización de un tipo determinado, haciendo especial referencia a la teoría de la unidad de título de imputación.

Palabras clave: delitos especiales, intraneus, extraneus, autoría, participación.

Abstract: Special crimes stand out precisely because they have an important element in their description, that is, they are executed only by an agent with specific qualities. From the foregoing, the following question arises: what is the responsibility of the subject who participates in a special crime and does not meet the specific qualities of that type? This issue is a question discussed by jurists and dogmatists, regarding the authorship and participation in the execution of these typical facts.

For this reason, the present work seeks to analyze and point out the criminal responsibility of the foreign agent as it is part of the realization of a certain type, making special reference to the theory of the unit of imputation title.

* Este trabajo se ha desarrollado en el marco del proyecto "Adolescencia y violencia sexual en Guanajuato: retos y oportunidades en materia de seguridad y prevención delictiva"; aprobada en la Convocatoria Institucional de Investigación Científica (CIIC, 2019; convenio no. 086/2019). La autora agradece el apoyo de la Universidad de Guanajuato.

${ }^{* *}$ Licenciada en Derecho. Egresada de la Maestría en Ciencias Jurídico Penales. Profesora de la materia Nociones generales de derecho en el curso propedéutico de la licenciatura en Derecho. Coordinación administrativa de los posgrados interinstitucionales en derechos humanos de la Universidad de Guanajuato.sol2oram@hotmail. com 
Keywords: special crimes, intraneus, extraneus, authorship, participation.

\section{Introducción}

Los delitos especiales se distinguen de los delitos comunes por tener una característica definida: el agente requiere una cualificación única para responder como autor o intraneus en el caso específico ${ }^{1}$. La autoría y participación en estos tipos penales es de singular importancia pues provoca un cuestionamiento respecto de las consecuencias jurídicas que cada uno de los intervinientes tendrá al realizarlos.

Existe la necesidad de analizar y dejar claro si la participación de un particular al que la doctrina se refiere como extraneus ${ }^{2}$ debe sancionarse de manera distinta a la del intraneus o si su intervención debe quedar impune por no actualizarse el supuesto aludido en los delitos especiales.

Resulta complicado determinar la solución que permita establecer la sanción para el extraneus, entendiéndolo como aquel que interviene en un delito especial y no cumple con las condiciones especiales exigidas por el tipo para considerarse autor del mismo. Si bien no debe quedar exento de responsabilidad jurídica, el argumento doctrinal dispone que no debe dársele el mismo tratamiento que al intraneus, quien, además de tener esa cualidad específica exigida en los delitos especiales para considerarse autor, asume ya un deber moral o institucional que cumplir ${ }^{3}$. Esos requisitos particulares del intraneus son directamente engendrados por el legislador para determinar quién se encuentra obligado por la posición moral, institucional o social y ser el sujeto al que se le exija el cumplimiento de sus responsabilidades, mismas que lo distinguen del resto de los individuos. Un comportamiento diferente al que debe cumplir es necesariamente reprochable y se legitima al Estado para que precise las consecuencias jurídicas propias al hecho, definiendo esa conducta del sujeto especial como intolerables, aún más que el de los delitos comunes.

Para ello, debe diferenciarse en el marco de los delitos especiales si esta figura corresponde a un delito propio o impropio; además de que, en cada caso, su análisis debe partir desde dos teorías distintas, como la teoría de la ruptura de título de imputación y la teoría de la unidad del título de imputación, con las cuales se obtienen las pautas para establecer los criterios que determinarán las consecuencias jurídicas ${ }^{4}$ en los delitos especiales para el extraneus ${ }^{5}$.

Será evidente la responsabilidad penal y la proporcionalidad de ésta para el extraneus una vez que se ha descrito en el tipo especial lo anterior, sin embargo, es importante determinar el grado de intervención del agente especial y dejar clara la responsabilidad del sujeto extraño, a pesar de no encontrarse en el mismo supuesto de moralidad o plano de compromiso institucional.

${ }^{1}$ SuÁrez SÁnchez, Alberto (2002), "El interviniente", Revista en Derecho Penal y Criminología, Bogotá, Colombia.pp. 12-29.

2 Ídem.

3 Ossandón, Ma Magdalena (2006), "Delitos especiales y de infracción de deber en el Anteproyecto de Código Penal", Revista de Política criminal. núm. 1, A4, p. 1-22.

4 Pero el problema no recae, singularmente, en la afirmación de imponer una pena al extraneus, pues queda claro que para el derecho penal no debe pasar desapercibida la actuación de un individuo, sino que se advierte como principal análisis el esclarecimiento de la cuantía de esa pena.

5 Rueda Martín, Ma. Ángeles (2018), “El fundamento de la atenuación facultativa de la pena del partícipe extraneus en un delito especial en el Código Penal Español”, InDret, núm. 3, julio, pp.2-39. 


\section{Punto de partida. Diferencia entre delitos especiales propios e impropios}

En la parte general y especial del derecho penal ${ }^{6}$ y derivado del análisis de la teoría del delito, debe distinguirse la diferencia entre delito común y delito especial, refiriéndose al primero como aquel que puede ser actualizado por cualquier sujeto. Sobre el delito común existe una referencia general en las legislaciones penales ${ }^{7}$.

A contrapartida, los delitos especiales son aquellos que solo pueden ser ejecutados por quienes ostentan una cualidad exigida en el tipo ${ }^{8}$, aunado al desarrollo real y actual del ejercicio de su actividad especial. Ahora bien, resulta difícil encuadrar la conducta de un extraño que no posee las cualidades elementales de los delitos especiales para ser sujeto de responsabilidad.

El concepto del delito especial tiene sus antecedentes en el estudio de la Ciencia del Derecho Penal en Alemania, pese a no existir una terminología exacta para referirse a este; por el contrario, desde la doctrina alemana hasta la italiana, se usaron diversos términos para lograr un reconocimiento legal como delitos especiales cuando se trataba de personas que realizaban una actividad específica, distinguiéndose de los delitos que podían cometerse por cualquier agente ${ }^{9}$.

Respecto al origen del concepto de delito especial, es necesaria una cualificación determinada, misma que está prevista en la descripción de los tipos en los códigos penales ${ }^{10}$. De lo anterior, se establece que solamente quienes tienen esa cualidad por el tipo especial pueden ser sujetos activos ${ }^{11}$. A grandes rasgos se advierte que el concepto de delito especial no da cabida a un agente que no cumpla con las características especificadas en la descripción de la conducta penalmente antijurídica. De esta manera, la conducta de un sujeto puede ser punible, a título de autor al margen de los delitos especiales, si y solo si su conducta es encuadrada en la legislación penal $^{12}$.

Ahora bien, debemos precisar la clasificación de los delitos especiales, los cuales se dividen en propios e impropios. Esta división hace referencia a aquellos delitos que no tienen correspondencia con uno común ${ }^{13} \mathrm{y}$ aquellos en los que un delito común es secundario al delito especialmente cualificado ${ }^{14}$, respectivamente.

La diferenciación entre un delito y otro es importante debido a que posteriormente se examinará la autoría y participación al respecto de cada uno, mismas características que aportarán y denotarán un punto de vista dogmático y legal sobresaliente para definir las responsabilidades jurídicas del intraneus y el extraneus ${ }^{15}$.

${ }^{6}$ Muñoz Conde, Francisco y García Arán, Mercedes (2010), Derecho Penal, parte general. 8ª. ed. Valencia, Tirant lo Blanch. p. 258.

7 Íbidem, p. 259.

8 Pedreira González, Féliz Ma. Autoría y participación [en línea], disponible en: http://app.vlex. com/\#vid/227895385, (consulta 30 septiembre de 2018).

9 Gómez Martín, Víctor, Los delitos especiales, [en línea], disponible en: http://hdl.handle.net/10803/1411, (consulta 26 de octubre de 2018).

10 Universidad de Navarra, Delitos comunes y delitos especiales, Navarra, España, [en línea], disponible en: http://www.unav.es/penal/crimina/topicos/delitoscomunesyespeciales.html, (consulta o1 de octubre de 2018).

${ }^{11}$ Ídem.

${ }^{12}$ Kierszenbaum, Mariano (2009), "La autoría y la participación en un delito especial”, Lecciones y ensayo, núm. 86. pp. 261-284.

${ }^{13}$ Muñoz Conde, Francisco y García Arán, Mercedes (2010), op. cit., nota 7, p. 259.

14 García Cavero, Percy (2009), "La pena del partícipe extraneus en los delitos especiales", Anuario de derecho penal, pp.115-126.

${ }^{15}$ Rebollo Vargas, Rafael (2000), Algunas consideraciones sobre autoría y participación en los delitos especiales. Particular referencia al delito de tortura. Anuario de Derecho Penal y Ciencias Penales. Universidad de Barcelo- 


\section{Lo propio y lo impropio de los delitos especiales}

Los delitos especiales propios no tienen correspondencia con un delito común ${ }^{16}$ y se encuentran caracterizados por una cualidad específica descrita en el tipo que además es actualizada por el agente especial y exige cumplir con ella para tener el título de autor del delito ${ }^{17}$. Es necesario recordar que, respecto a la perspectiva de algunos doctrinistas penales como Francisco Muñoz Conde $^{18}$, aquel sujeto que no cumpla con los requisitos específicos de los delitos especiales no podrá tener responsabilidad penal, por no actualizarse el tipo ${ }^{19}$.

En este sentido, el delito especial propio debe realizarse por un sujeto con cualidades especiales; a contrario sensu, no representa existencia a la vista del derecho penal, es decir, el agente activo es un elemento significativo para la constitución del delito especial propio que, además, es autónomo por no subordinarse a un delito común. Se trata de un sujeto activo que ostenta una condición natural o jurídica frente al Estado o la sociedad y que ante su ausencia se atendería a la atipicidad del hecho ${ }^{20}$.

Los delitos especiales impropios solo tienen correspondencia con algún delito común cuando este último es realizado por sujetos con características no específicas, lo cual transfigura la conducta en una autónoma con punibilidad distinta, por supuesto ${ }^{21}$. En los delitos especiales impropios no debería existir cuestionamiento alguno referente a la responsabilidad de un extraño en el tipo una vez que es posible encuadrar su conducta en un delito común en correspondencia $^{22}$; y si fuese un sujeto determinado por una cualidad especial, se trata entonces de una modificación de imputabilidad en la conducta ${ }^{23}$.

De acuerdo con las particularidades de estos delitos, se distingue que además de permitir una modalidad para individuos especiales también admite una para los sujetos que no satisfacen la descripción del tipo ${ }^{24}$, además de existir una conducta actualizada por un agente específico, quien puede estar subordinado a la conducta común de otro, cuya actuación sea indispensable para que exista el delito especial ${ }^{25}$. No es determinante la conducta del extraño, toda vez que su actuar muestra correspondencia con un delito común ${ }^{26}$ y estas particularidades son concomitantes con los delitos especiales impropios.

\section{Autoría y participación}

Hablaremos ahora del concepto unitario y diferenciador de autor que ha creado la doctrina para establecer la participación y responsabilidad de los intervinientes en el hecho antijurídico ${ }^{27}$.

\footnotetext{
na, [en línea], disponible en: http://vlex.com/vid/autoria-particular-referencia-tortura-381312, (consulta el 20 de octubre de 2018).

${ }^{16}$ García Cavero, Percy (2009), op. cit., nota 15, p. 117.

17 Ídem.

${ }^{18}$ Muñoz Conde, Francisco y García Arán, Mercedes (2010), op. cit., nota 7, p. 259.

19 Rebollo Vargas, Rafael (200o), op. cit., nota 16.

${ }^{20}$ Avelar Valencia, Carlos Ernesto (2012), "Complicidad del extraneus en los delitos especiales propios" Universidad del Salvador, p. 1-171.

${ }^{21}$ Ídem.

${ }^{22}$ Ídem.

23 Ídem.

${ }^{24}$ Universidad de NAVArRa, op. cit., nota 11 (consulta o1 de octubre de 2018).

${ }^{25}$ Ídem.

${ }^{26}$ Ídem.

27 SuÁrez SÁnchez, Alberto (2002), op. cit. nota 2. p. 15. 
Para ello identifica el concepto unitario de autor, renunciando a distinguir entre autor y partícipe, así como a la accesoriedad, para considerar a todos los intervinientes como autores. Es decir, admite una intervención general bajo un único concepto de autor.

Consecuentemente, no consigue imponer un vínculo de accesoriedad entre todos los intervinientes ${ }^{28}$ y es por ello por lo que el concepto unitario de autor es insostenible en la praxis una vez que la legislación no objeta ni contradice la existencia y diferencia entre el autor y el partícipe. Es así como podemos percatarnos que dar el mismo tratamiento a cada interviniente, como autor, obstaculiza la delimitación de la responsabilidad jurídica de acuerdo con la punibilidad del agente por haber ejecutado acciones como autor, inductor o cómplice. Por ello es necesario establecer categorías jurídicas que expliquen el grado de intervención ${ }^{29}$.

Entonces, el concepto diferenciador de autor acepta la accesoriedad y distingue al autor del partícipe; será el autor quien represente el papel principal del hecho y el partícipe figure como el sujeto subordinado a la conducta del primero ${ }^{30}$. Al margen de este concepto, es autor aquel que determina el resultado del hecho típico, pero distingue otros grados de responsabilidad como la del partícipe, lo cual permite establecer las limitantes para disponer la obligación jurídica de todos los intervinientes.

Se reconoce al autor como la persona que tiene el ánimo de ejecutar una conducta para dañar un bien jurídico o tiene el interés de provocar ese resultado, diferenciándolo del partícipe, quien no tiene la intención de asumir como propio el hecho ${ }^{31}$. Ser partícipe se refiere a realizar una conducta autónoma que implique una consecuencia jurídica, pero que no constituye el perfil de autoría, sin embargo, permite establecer la culpabilidad de cada uno de forma individual ${ }^{32}$.

En cualquier caso, se establece que el autor será quien pueda realizar el tipo, directamente o por medio de otro, y quien sostenga un interés por dañar un bien jurídico. En el marco de los delitos especiales — con particular referencia a los delitos especiales propios-, el autor será toda persona que satisfaga las condiciones específicas descritas en el tipo penal, ya sea como autor directo o como autor mediato. Este último se define por la necesidad de discernir la problemática de la autoría inmediata, pues, si el instrumento no actualiza las descripciones especiales, el hecho no podrá existir a la luz del derecho penal; se trata de un instrumento no cualificado que no ha desarrollado cierto comportamiento antijurídico ${ }^{33}$.

Fue en Alemania donde se concibió la figura del autor mediato para resolver las dudas de punibilidad al no podérsele imponer una pena al instrumento. Es por ello, por lo que surgió la necesidad de establecer la responsabilidad de quien utiliza a otro para la consumación de una conducta antijurídica, con independencia de si aquel instrumento consolida cualidades especiales.

\footnotetext{
28 Gómez González, Orlando T., Concepto unitario de autor, [en línea] disponible en: https://app.vlex. com/\#vid/180076, (consulta 20 de octubre de 2018).

${ }^{29}$ Roxin, Claus (2014), Derecho Penal, Parte General, Especiales formas de aparición del delito, Thomson Civitas. t. II, pp. 64-66.

30 Gómez GonzÁlez, Orlando T., op. cit., nota 29 (consulta 20 de octubre de 2018).

${ }^{31}$ Ídem.

32 Roxin, Claus (2014), op. cit., nota 30, p. 204.

33 Rebollo Vargas, Rafael (200o), op. cit., nota 16.
} 


\section{IV.1. Autoría en los delitos especiales}

Se considera autor a quien realice una conducta típica configurando la acción u omisión al que hace referencia el verbo rector del delito ${ }^{34}$. Asimismo, el Código Penal para el Estado de Guanajuato define al autor como aquel que realiza por sí, por medio de otro o por varios en común un delito ${ }^{35}$.

Los delitos especiales reconocen solamente al sujeto cualificado como autor en el tipo e incluso admiten la coautoría solo si esos agentes cumplen con la descripción del tipo penal especial. Sin embargo, la autoría mediata no es aceptada para el extraneus. En efecto, ser autor mediato significa ser autor principal y en estos supuestos no es posible delimitar las cualidades de dicho sujeto al margen de los delitos especiales ${ }^{36}$.

Si a pesar de lo anterior resulta complicado entender la autoría desde la perspectiva de los delitos especiales, se recomienda analizarlo desde la teoría del dominio del hecho, la cual puede ser un elemento determinante para comprender quiénes tienen las posibilidades de poseer la calidad de autor ${ }^{37}$. Y precisamente del análisis de esta teoría se desprende que es aún más sencillo distinguir si un sujeto realizó una conducta por sí o por instrucciones de otro.

Derivado del estudio de la teoría del delito y del examen realizado a la teoría del dominio del hecho, el autor es el agente que puede realizar los actos típicos ${ }^{38}$, es decir, quien tiene el dominio de la consumación del hecho. Bajo este criterio, no se admite que quien no puede dominar el hecho se estime como autor, sin embargo, puede considerársele como partícipe del acto.

Dominar el hecho implica dominar también la acción, entendiendo por esto, que el sujeto será quien realice por sí el delito; o puede manifestarse también con el dominio de la voluntad, lo que implica actuar por medio de otro de tal manera que la voluntad de este se encuentre subordinada a la voluntad del primero. A esto se le conoce actualmente como la autoría mediata.

Finalmente, el dominio del hecho puede representarse por el dominio funcional del hecho, lo cual significa la realización del tipo penal por varias personas con una distribución de funciones o actividades dentro de la ejecución del tipo, lo que a la vista del derecho penal se conoce como coautoría $^{39}$. La teoría del dominio del hecho supone que quien lleva a cabo el injusto penal asume también el dolo que implica su desarrollo y es el único que puede actuar conforme a su voluntad.

Roxin refiere que para determinar la autoría es necesario, no solo estudiar la teoría del dominio del hecho - al que define como el dominio de la acción final que dará el resultado típico-, sino también, analizar los delitos de infracción de deber, ya que, después de todo, el intraneus es quien ha obtenido una obligación moral o institucional y, por ende, el extraneus no puede

\footnotetext{
34 Reyes Echandía, Alfonso (2017), Derecho Penal, Parte General, Bogotá, Colombia, Temis obras jurídicas, pp. 100-107.

35 Código Penal para el Estado de Guanajuato. Parte general. Título II, capítulo III. Artículo 20. Última reforma publicada en el POGEG el 24 de septiembre de 2018, [en línea] disponible en: http://www.congresogto. gob.mx/uploads/codigo/pdf/2/C_DIGO_PENAL_DEL_EDO_DE_GTO_PO_D337_24sse2018.pdf, (consulta 15 de octubre de 2018).

${ }^{36}$ Pedreira González, Féliz Ma., op. cit., nota 9.

37 Rueda Martín, Ma. Ángeles (2018), op. cit. nota 6, p. 13.

${ }^{38}$ CRespo, Eduardo Demetrio (2016), La tentativa en la autoría mediata y en la actio libera in causa: una contribución al estudio del fundamento de punición y comienzo en la tentativa, Granada, [en línea], disponible en: http:// www.cienciaspenales.net/files/2016/o7/8.2.7lh-roxin.pdf, (consulta 26 de octubre de 2018).

39 Gómez Benítez, José Manuel (1984), El dominio del hecho en la autoría, Universidad Complutense, [en línea] disponible en: http://www.cienciaspenales.net, (consulta 26 de octubre de 2018).
} 
considerarse como autor o coautor, toda vez que en estricto sentido y tomando en cuenta la teoría del dominio del hecho, él es quien domina la acción final y sería suficiente para ser autor; sin embargo, no ostenta esa obligación de custodiar un deber ${ }^{40}$.

Refiriéndose ahora a la posibilidad de reconocer al extraneus como autor mediato, siendo el intraneus el instrumento, se delimita este problema al recordar que se le llama extraneus por no poseer las cualidades que el tipo requiere y se replantea la pregunta de quién tiene el dominio final del hecho, sobre todo tratándose de delitos especiales propios. En ese supuesto, el instrumento sí tiene una condición especial, es decir, sostiene una posición necesaria en los delitos especiales $^{41}$.

Entonces, el agente extraño, a pesar de utilizar al intraneus como instrumento para actualizar un hecho delictivo, no se considerará autor mediato al no cumplir con las particularidades de un autor especial, es decir, por la ausencia de elementos típicos de carácter personalísimo ${ }^{42}$.

De lo anterior se presume que, el sujeto extraño no puede considerarse autor mediato por no ostentar una peculiaridad específica y por no tener el dominio final de la realización del hecho. Podrá contemplarse solamente como autor a aquel que tenga una característica especial descrita por la legislación, de lo contrario, el particular solo podrá tener la calidad de partícipe, por carecer del elemento especial indispensable puntualizado en el tipo y tendrá solamente una conducta concomitante a la del intraneus ${ }^{43}$.

\section{IV.2. Participación en los delitos especiales}

Ante la figura del autor, el legislador creó la del partícipe para todos los intervinientes que no tienen las características exigibles por la norma para ser autores; como ejemplo, el Código Penal para el Estado de Guanajuato, el cual refiere, en su artículo 20, que será partícipe quien sea instigador o cómplice ${ }^{44}$. Entendiendo como instigador a aquel que dispone de la voluntad de una persona para la comisión de un delito y al cómplice, como el que proporciona ayuda a otro individuo para la ejecución de una conducta delictiva ${ }^{45}$.

La participación existe siempre que se haya realizado un tipo penal por un autor o coautores y es considerada como una conducta subordinada a la conducta del autor, pues no puede ser castigado un partícipe si la acción de otro, como sujeto principal, no se considera como conducta típica. El partícipe coopera con otro sujeto para agotar la descripción del tipo de manera dolosa, una vez que conoce el interés que tiene el autor de dañar el bien jurídico ${ }^{46}$.

Como se ha mencionado anteriormente, el partícipe es conocedor de la intención del autor respecto a la pretensión de dañar un bien jurídico. Bajo este contexto y a pesar de ser consciente de los propósitos del autor, el partícipe quiere ser parte del hecho con toda la intención de coo-

\footnotetext{
${ }^{40}$ Roxin, Claus (2014), op. cit., nota 30 pp. 179-181.

${ }^{41}$ Scheller D’Angelo, André (2011), "La teoría del dominio del hecho en la legislación penal colombiana”, Universidad cooperativa de Colombia seccional Santa Marta, Artículo de investigación, núm. 35, pp. $244-262$.

42 Gimbernat Ordeig, Enrique (2006), Autor y cómplice en Derecho Penal, Buenos Aires, Argentina. Editorial B de f, pp. 199-202.

${ }^{43}$ Gómez Pavajeau, Carlos Arturo (2004), Autoría y participación en los delitos de omisión. Colombia, [en línea], disponible en: file://C:/Users/sol2o/AppData/Local/Temp/1033-Texto\%2odel\%2oartículo-3624-1-10-20101004. pdf, (consulta 27 de octubre de 2018).

44 Código Penal para el Estado de Guanajuato. op. cit., nota 36 (consulta 25 de octubre de 2018).

45 Íbidem, artículo 21.

${ }^{46}$ Muñoz Conde, Francisco y García Arán, Mercedes (2010), op. cit., nota 7, p. 439.
} 
perar o animarlo en la realización del tipo con una acción meramente dolosa ${ }^{47}$. En todo caso, solo puede ser partícipe aquella persona que encuadre en las siguientes descripciones: porque no tiene las características específicas del delito para ser autor o porque su conducta se limita a ser únicamente una aportación atenuante de la conducta principal.

En el momento en que el autor realiza la conducta, surte efectos la cooperación o instigación del partícipe en ese hecho. Eso no significa que el autor sea quien decida la responsabilidad del partícipe, pues de ser así se desnaturaliza el principio de la responsabilidad penal, la cual refiere que cada uno de los intervinientes será incriminado por el hecho propio y no por el de otro ${ }^{48}$. La función del partícipe es apoyar o incitar al autor para ejecutar un tipo penal y será este último quien considere si integra esa conducta a su dominio o la deja fuera ${ }^{49}$.

Ahora bien, después de establecer la diferencia entre el autor y el partícipe podemos distinguir, de la clasificación de este último, al inductor y al cómplice. El primero se refiere a aquel que establece en otra persona la idea de realizar un hecho delictivo, es decir, quien tiene una relación directa con el inducido y es capaz de influir en su decisión para ejecutar el delito, de tal manera que logre de forma eficaz que el inducido inicie, por lo menos, a realizar el tipo penal ${ }^{50}$. Sin embargo, el cómplice es quien contribuye con otro para la realización de un delito, de tal suerte que no podría considerarse autor. Su conducta será estimada peligrosa porque su aportación coadyuba a acelerar o mejorar la acción ${ }^{51}$.

Bajo este contexto, el extraneus podrá adquirir la calidad de partícipe en la realización de un delito y bastará con analizar su participación para establecer si lo hizo como cómplice o instigador. Instigador será si impulsa al intraneus a ejecutar un tipo penal o cómplice cuando ha colaborado con el intraneus antes, durante o después de la realización de un delito, considerada su conducta como accesoria de quien infringe la norma ${ }^{52}$.

Después de conocer la disparidad entre un delito especial propio y uno impropio, corresponde ubicar la participación y consecuencia jurídica del extraneus en ambos. La participación del extraneus en los delitos especiales impropios sin problema obtiene una responsabilidad legal una vez acreditada la conducta descrita en el delito común en correspondencia con el delito especial. Si el partícipe lleva a cabo actos ejecutivos que colaboren con el autor, entonces responderá por el delito común realizado ${ }^{53}$.

En cambio, establecer la responsabilidad jurídica que tiene el extraneus tratándose de delitos especiales propios se complica en tanto no se tiene un delito común base. La doctrina alemana propone sancionar al extraño de la misma forma en que se castiga al intraneus, pues si en los delitos especiales impropios se parte de un delito base para establecer la responsabilidad del extraneus, en el caso de los delitos especiales propios será este mismo del que se parta para castigar al agente extraño. Sin embargo, la doctrina no considera justo que el extraneus reciba la misma pena, ya que es el intraneus quien tiene bajo su cuidado un deber social o institucional ${ }^{54}$.

\footnotetext{
47 Íbidem, p. 440.

${ }^{8}$ SuÁrez Sánchez, Alberto (2002), op. cit., nota 2, p. 16.

49 Ídem.

50 Muñoz Conde, Francisco y García Arán, Mercedes (2010), op. cit., nota 7, p. 444.

${ }^{51}$ Íbidem, p. 446.

52 SuÁrez Sánchez, Alberto (2002), op. cit., nota 2, p. 20.

53 Gimbernat Ordeig, Enrique (2006), op. cit., nota 43, p. 22.

54 Íbidem, pp. 223-228.
} 


\section{IV.3. Principio de accesoriedad}

Se refiere a que una conducta delictiva debe ser ejecutada por el autor para que exista la posibilidad de configurarse la responsabilidad de un partícipe ${ }^{55}$. Con independencia de la culpabilidad del autor, si no existe una figura primaria que por lo menos comience con la ejecución del tipo, no puede culparse a otro como partícipe si su conducta no se encuentra subordinada a la del autor ${ }^{56}$. Este principio de accesoriedad se explica fácilmente entendiendo que el concepto se fundamenta en la existencia de la dependencia de la conducta del partícipe respecto de la conducta del autor y esa sujeción consiste en la falta de autonomía criminal de la conducta del partícipe, determinando así la naturaleza jurídica de la accesoriedad en la participación. De esta manera, la estimación jurídica de la participación depende de la conducta del autor principal ${ }^{57}$.

Este principio se puede manifestar de la siguiente manera: como accesoriedad limitada, máxima y mínima, en la accesoriedad mínima basta con que el autor haya concretado un delito para que la conducta del partícipe sea punible. Diferente de la accesoriedad máxima, en la que se requiere que el autor agote una conducta culpable, punible y antijurídica para establecer la punibilidad del partícipe ${ }^{58}$.

En cambio, la accesoriedad limitada solo necesita el inicio de una conducta antijurídica concurrida por el autor, sin importar que no se haya establecido la culpabilidad y punibilidad, para constituir la responsabilidad del partícipe. Lo anterior, por lo que respecta al alcance intensivo de la accesoriedad. Ahora, el alcance extensivo de accesoriedad refiere que la participación es dependiente del delito ejecutado por el autor o, al menos, de la tentativa ${ }^{59}$. Por lo tanto, la esencia de la participación se somete al hecho principal.

\section{Teorías respecto a la intervención del extraneus en los delitos especiales}

Ante lo complejo que resulta determinar la responsabilidad del extraneus en los delitos especiales propios y considerar la posibilidad de enmarcar su conducta como partícipe de un delito especial que exige cualidades específicas para los intervinientes, se debate desde dos teorías para resolver ese enigma: la teoría de la ruptura del título de imputación y la teoría de la unidad del título de imputación ${ }^{60}$.

\section{V.1. Teoría de la ruptura del título de imputación}

Esta teoría define que únicamente los intraneus serán los responsables de los delitos especiales por ser quienes cumplen con las cualidades específicas del tipo, mientras que los extraneus solo

\footnotetext{
${ }^{55}$ Universidad de Navarra, Accesoriedad de la participación, Navarra, España, [en línea], disponible en: http:// www.unav.es/penal/crimina/topicos/accesoriedadparticipacion.html, (consulta 10 de noviembre de 2018).

${ }^{56}$ Muñoz Conde, Francisco y García Arán, Mercedes (2010), op. cit., nota 7, p. 439.

57 Gómez González, Orlando T. (2017), Participación criminal: análisis doctrinal y jurisprudencial, [en línea], disponible en: https://2019.vlex.com/\#vid/180091 (consulta 10 de noviembre de 2018).

${ }^{58}$ Universidad de NaVArRa, op. cit., nota 56 (consulta 10 de noviembre de 2018).

59 Avelar Valencia, Carlos Ernesto (2012), op. cit., nota 21, p. 69.

${ }^{60}$ García Cavero, Percy (2009), op. cit., nota 15, p. 116.
} 
tendrán responsabilidad jurídica cuando su conducta concurra en la descripción de un delito común.

Quienes apoyan esta teoría manifiestan que las descripciones del tipo especial no pueden servir como base para establecer la punibilidad del extraño interviniente. Es sencillo aplicar esta teoría cuando de delitos especiales impropios se trata, pues el intraneus responderá como autor o partícipe de un delito especial de acuerdo con la intervención que haya tenido en él y el extraneus será autor del delito común subyacente, si fue este último quien utilizó al intraneus como instrumento para realizar una conducta delictiva.

El problema se presenta cuando se trata de delitos especiales propios y la teoría de la ruptura del título de imputación nos dice que los intraneus responderán como autores de los delitos especiales y no existirá punibilidad para el extraneus por no presentarse un delito común subyacente $^{61}$.

La crítica para esta teoría es que tiene un defecto importante, pues, en el caso de los delitos especiales impropios, el intraneus tendrá responsabilidad como autor de un delito especial si tuvo el dominio del hecho y el extraneus como partícipe de un delito común que realmente no se cometió si prestó ayuda al intraneus o lo determinó para realizar el tipo. Sin embargo, en los delitos especiales propios, si fue el extraneus quien tuvo el dominio del hecho, será el intraneus quien se responsabilice como partícipe de un delito que no existe, pues al extraneus no lo acepta como posible autor de delitos especiales. Si recordamos el principio de accesoriedad, es necesario que exista el autor de un hecho, y que por lo menos comience a realizar la conducta, para que pueda existir un partícipe. Siendo así, el intraneus tampoco tendría responsabilidad penal ${ }^{62}$.

En consecuencia, los intervinientes extraños no podrán tener responsabilidad de un delito especial propio, por lo tanto, esta teoría genera un vacío de punibilidad ${ }^{63}$.

\section{V.2. Teoría de la unidad del título de imputación}

Esta teoría consagra el principio de accesoriedad, pues distingue al autor y al partícipe en la ejecución de los delitos especiales. Está de acuerdo en que un extraño no puede ser tratado como autor ni como autor material de delitos especiales, pero sí considera necesario responsabilizarlo como partícipe. Lo anterior, porque la finalidad del derecho penal es la protección de bienes jurídicos y no se puede permitir que quienes hayan realizado un delito queden impunes por no alinearse a las características especiales determinadas por el tipo ${ }^{64}$.

El extraneus que coopera con un intraneus en la comisión de un delito especial no será considerado como partícipe de un delito común, sino de un delito especial, que es aún más grave. Existe, pues, una unidad de intenciones de afectar un bien jurídico propia de personas que tienen las condiciones determinadas por el tipo y por personas que no cumplen con ellas ${ }^{65}$.

Un extraño, por haber realizado un delito, será responsable del mismo con independencia de las cualidades especiales exigidas por el tipo, pues basta con haber tenido la intención de dañar

\footnotetext{
${ }^{61}$ Abanto Vázquez, Manuel (2014), “Autoría y participación y la teoría de los delitos de infracción de un deber”, Revista Penal de España núm.14, [en línea], disponible en: https://www.terragnijurista.com.ar/doctrina/vasquez. htm, (consulta 14 noviembre de 2018).

${ }^{62}$ Ídem.

63 García Cavero, Percy (2009), op. cit., nota 15, p. 116.

${ }^{64}$ Abanto VázQuez, Manuel, op. cit., nota 62 (consulta 14 noviembre de 2018).

65 Peña Ossa, Erleans de Jesús (1992), "La participación en los delitos especiales”, Nuevo Foro Penal, Política Criminal, núm. 15, pp. 17-34.
} 
un bien jurídico. Esto afianza la teoría de la unidad del título de imputación, ya que el extraneus responde por el delito especial y no por un delito común, de esta manera, deja de lado la distinción entre un delito especial propio de uno impropio ${ }^{66}$.

La teoría de la unidad del título de imputación no permite juzgar al interviniente por delitos diferentes; deben responder por el mismo delito como autor o como partícipe. A pesar de que el extraneus determine al intraneus o coopera con él para ejecutar un delito, no podrá ser considerado como autor, pues es el intraneus quien tiene a su alcance la posibilidad de evitar la afectación del bien jurídico; sería diferente si el intraneus no realiza la conducta y el extraneus constituye acciones que por sí ya configuran un delito diferente ${ }^{67}$.

Finalmente, puede definirse lo siguiente: el extraneus debe responsabilizarse por su conducta, que implica ya una afectación a un bien jurídico, con independencia de si conoce o no las cualidades especiales del intraneus, pues su conducta implica ya un hecho ilícito.

La responsabilidad del extraneus depende entonces del delito especial de que se trate y, desde el estricto punto de vista jurídico-penal, en tratándose de delitos especiales propios. La responsabilidad del extraneus versará en ser juzgado por ese delito especial como instigador o cómplice, con base en su participación, para evitar que el extraño quede impune ante el hecho. En cambio, con los delitos especiales impropios, el extraneus tendrá responsabilidad, sobre el delito común adyacente al especial, en calidad de autor ${ }^{68}$.

\section{Reflexión final}

Podemos determinar que la legislación del Estado de Guanajuato, en una argumentación y fundamentación similar a otras legislaciones ${ }^{69}$, se decanta por establecer como fundamento, en el ámbito nuclear de la autoría y participación, el principio de la accesoriedad limitada, es decir, la responsabilidad del partícipe resulta accesoria y dependiente respecto del autor. De esta manera, existe un obstáculo importante para poder fundar la responsabilidad del extraneus respecto de aquellos delitos especiales propios. La idea de esta breve exposición es encontrar un punto de solución factible en la codificación punitiva para el Estado de Guanajuato. No debemos obviar que, si bien es cierto que la actuación del extraneus no encuadra en los extremos de la tipología especial en el carácter de la calidad especial referida en el tipo, no menos cierto es que los más elementales principios constitucionales y legales obligan a sancionar al partícipe extraneus por la participación dentro del ámbito de su propio injusto.

La tarea aquí planteada es ubicar la sanción del partícipe en el delito especial propio cuando reviste la característica de ser extraneus, sobre todo para el Código Penal del Estado de Guanajuato, sin perder de vista que la actuación de este personaje se limita a favorecer. Toda vez que es en los delitos especiales propios donde recae el problema de solución y delimitación de

\footnotetext{
66 Íbidem, p. 29.

67 Íbidem, p. 31.

68 Íbidem, p. 34 .

${ }^{69}$ Los artículos 27 a 29 y 300 del código Penal Español, para el caso de Guanajuato, dicho principio de accesoriedad limitada se encuentra previsto en los artículos 24 y 25 de nuestro código penal que señala: Artículo 24. Las causas personales de exclusión de la pena sólo favorecen a los autores o partícipes en quienes concurran.

Artículo 25. Las calidades, relaciones personales o elementos de carácter subjetivo que constituyan la razón de atenuación o agravación de la punibilidad, sólo influirán en la de aquéllos en quienes concurran.
} 
la responsabilidad jurídica del agente extraño, ninguna regla de solución debe dejar de lado que el análisis del desvalor del extraneus solo resulta conducente mediante el examen conjunto de la conducta desarrollada por el autor.

Existen criterios jurídicos y doctrinales que se centran en fundamentar el ámbito de punibilidad del extraneus, derivado por quienes hayan infringido los deberes extrapenales tutelados por el ordenamiento jurídico, con independencia de la vulneración de los grados de intervención de este en el delito especial. Jordi Casas, por ejemplo, señala que cuando el extraneus conduce al intraneus a realizar un delito es suficiente para sancionar la conducta del primero, ya que existe la intención dolosa del exraneus de provocar una conducta igualmente dolosa que la del intraneus. Aun cuando el intraneus sepa que su actuar es ilegal, el extraneus determinó la conducta de aquel y ese acto arbitrario y antijurídico justifica su responsabilidad ${ }^{70}$.

Lo interesante de esta aproximación es fundar la sanción del extraneus, ya no derivada de un principio de accesoriedad limitada, sino de la infracción de deberes fundamentales en colaboración.

Resulta entonces que la legislación de Guanajuato omite la regulación de estos aspectos importantes y en este análisis es importante establecer pautas que permitan esclarecer el grado de intervención del agente extraño y su responsabilidad jurídica. De lo contrario, el juzgador tendrá que establecer la impunidad del interviniente extraneus, pues el código de Guanajuato, basado en la accesoriedad limitada, no permite los puntos de solución diversos.

En este orden de ideas, se proponen puntos de solución sin dejar de lado el principio de accesoriedad limitada que utiliza nuestra legislación, el cual es correcto, atendiendo a la infracción de los deberes fundamentales y dándole utilidad a la teoría de la unidad de título de imputación, la cual permite ampliar las posibilidades de establecer una responsabilidad jurídica para el extraneus - según la intervención que haya tenido en el hecho ilícito-, para la generalidad de casos de autoría y participación en los delitos especiales, por ser elementos más específicos, tratándose de la intervención de un extraneus.

\section{Bibliografía}

Авanto VÁzquez, Manuel (2014), “Autoría y participación y la teoría de los delitos de infracción de un deber", Revista Penal de España, núm.14, [en línea], disponible en: https:// www.terragnijurista.com.ar/doctrina/vasquez.htm.

Avelar Valencia, Carlos Ernesto (2012), "Complicidad del extraneus en los delitos especiales propios”, Universidad del Salvador, pp. 1-171.

Casas Hervilla, Jordi (2018), “La participación del extraneus en el delito de prevaricación administrativa: principales problemas y propuestas para su solución, Estudios penales y criminológicos", núm. 38, pp. 589-642.

Código Penal para el Estado de Guanajuato. Última reforma publicada en el POGEG el 24 de septiembre de 2018, [en línea], disponible en: http://www.congresogto.gob.mx/ uploads/codigo/pdf/2/C_DIGO_PENAL_DEL_EDO_DE_GTO_PO_D337_24sse2018. pdf.

\footnotetext{
70 Casas Hervilla, Jordi (2018), "La participación del extraneus en el delito de prevaricación administrativa: principales problemas y propuestas para su solución, Estudios penales y criminológicos”, núm. 38, pp. 604-615. 
Crespo, Eduardo Demetrio (2016), La tentativa en la autoría mediata y en la actio libera in causa: una contribución al estudio del fundamento de punición y comienzo en la tentativa, Granada, [en línea], disponible en: http://www.cienciaspenales.net/files/2016/o7/8.2.7lhroxin.pdf.

García Cavero, Percy (2009), “La pena del partícipe extraneus en los delitos especiales”, Anuario de derecho penal, pp. 115-126.

Gimbernat Ordeig, Enrique (2006), Autor y cómplice en Derecho Penal, Buenos Aires, Argentina, Editorial B de f.

Gómez Benítez, José Manuel (1984), El dominio del hecho en la autoría, Universidad Complutense, [en línea], disponible en: http://www.cienciaspenales.net.

Gómez González, Orlando T., Concepto unitario de autor, [en línea], disponible en: https:// app.vlex.com/\#vid/180o76.

(2017), Participación criminal: análisis doctrinal y jurisprudencial, [en línea], disponible en: https://2019.vlex.com/\#vid/180o91

Gómez Martín, Víctor, Los delitos especiales, [en línea], disponible en: http://hdl.handle. net $/ 10803 / 1411$.

Gómez Pavajeau, Carlos Arturo (2004), Autoría y participación en los delitos de omisión, Colombia, [en línea], disponible en: file://C:/Users/sol2o/AppData/Local/Temp/1033-Texto\%20del\%20artículo-3624-1-10-20101004.pdf.

Kierszenbaum, Mariano (2009), "La autoría y la participación en un delito especial”, Lecciones y ensayo, núm. 86, pp. 261-284.

Muñoz Conde, Francisco y García Arán, Mercedes (2010), Derecho Penal, parte general, $8^{\text {a }}$. ed., Valencia, Tirant lo Blanch, p. 258.

Ossandón, Ma Magdalena (2006), "Delitos especiales y de infracción de deber en el Anteproyecto de Código Penal”, Revista de Política criminal, núm. 1, A4, p. 1-22.

Pedreira GonzÁlez, Féliz Ma., Autoría y participación, [en línea], disponible en: http://app. vlex.com/\#vid/227895385.

PeÑa Ossa, Erleans de Jesús (1992), “La participación en los delitos especiales”, Nuevo Foro Penal, Política Criminal, núm. 15, pp. 17-34.

Rebollo Vargas, Rafael (200o), Algunas consideraciones sobre autoría y participación en los delitos especiales. Particular referencia al delito de tortura. Anuario de Derecho Penal y Ciencias Penales, Universidad de Barcelona, [en línea], disponible en: http://vlex.com/ vid/autoria-particular-referencia-tortura-381312.

Reyes Echandía, Alfonso (2017), Derecho Penal, Parte General. Bogotá, Colombia. Temis obras jurídicas, pp. 100-107. 
Roxin, Claus (2014), Derecho Penal, Parte General Tomo II, Especiales formas de aparición del delito, Thomson Reuters-Civitas.

Rueda Martín, Ma. Ángeles (2018), "El fundamento de la atenuación facultativa de la pena del partícipe extraneus en un delito especial en el Código Penal Español”, InDret, núm. 3, julio, pp. 2-39.

Scheller D’Angelo, André (2011), “La teoría del dominio del hecho en la legislación penal colombiana”, Universidad cooperativa de Colombia seccional Santa Marta, Artículo de investigación, núm. 35, pp. 244-262.

SuÁrez SánChez, Alberto (2002), "El interviniente", Revista en Derecho Penal y Criminología, Bogotá, Colombia, pp. 12-29.

Universidad de Navarra, Accesoriedad de la participación, [en línea], disponible en: http:// www.unav.es/penal/crimina/topicos/accesoriedadparticipacion.html.

Universidad de Navarra, Delitos comunes y delitos especiales, [en línea], disponible en: http://www.unav.es/penal/crimina/topicos/delitoscomunesyespeciales.html. 